\title{
BUERGER EXERCISE DAN EDUKASI PERAWATAN KAKI PADA PENDERITA DIABETES DAN HIPERTENSI DALAM UPAYA MENURUNKAN RESIKO GANGGUAN VASKULAR
}

\author{
Ika Nur Pratiwi ${ }^{1}$, Lingga Curnia Dewi ${ }^{1}$, Ika Yuni Widyawati ${ }^{1}$ \\ ${ }^{1}$ Universitas Airlangga, Surabaya, Indonesia \\ ikanurpratiwi@fkp.unair.ac.id
}

\begin{abstract}
Abstrak: Hipertensi dan diabetes melitus (DM) yaitu penyakit kronis yang membutuhkan perawatan berkelanjutan sebagai upaya untuk mengendalikan tekanan darah dan kadar gula darah. Keduanya memiliki kerentanan mengalami gangguan vaskular sehingga aliran sirkulasi darah tidak lancar, rentan mengalami gangguan ekstremitas kaki yang bermanifestasi menjadi sumbatan pada pembuluh darah, ulkus bahkan amputasi. Situasi pandemi akibat COVID-19, mengharuskan penderita tetap berada dirumah saja terutama pada individu dengan komorbid seperti hipertensi dan DM yang beresiko lebih tinggi tertular Covid-19, jika tidak ada situasi darurat. Tujuan pengabdian kepada masyarakat (PKM) ini adalah untuk memberikan pendidikan dan pelatihan buerger exercise dan perawatan kaki dalam upaya menurunkan resiko gangguan vaskular penderita DM dan hipertensi. Lokasi Kegiatan PKM di Lembaga Kesejahteraan Sosial Hargo Dedali, Surabaya dengan memperhatikan protokol kesehatan yang keta dengan melibatkan 21 peserta dengan rerata usia 59 tahun, 6 peserta $(28,6 \%)$ mengalami hipertensi, 7 peserta $(33,3 \%)$ mengalami DM dan 8 orang $(38,1 \%)$ mengalami keduanya. Metode yang digunakan dalam PKM ini adalah pendekatan Community Based Research (CBR). Evaluasi akhir program PKM dengan membandingkan nilai pre test dan post test terhadap pengetahuan dan kondisi vaskular kaki serta pemeriksaan Ankle Brachial Index (ABI). Hasil pengukuran terhadap tingkat pengetahuan $p=0,000(p<0,05)$, kuesioner Vascular Quality of Life dengan $p=0,001$ $(p<0,05)$ dan ABI dengan $p=0,002(p<0,05)$ sehingga terdapat perbedaan yang bermakna antara sebelum dan sesudah diberikan pendidikan dan pelatihan dalam hal peningkatan pengetahuan dan perbaikan fisik kondisi vaskular. Pemberdayaan penderita DM dan hipertensi melalui pendidikan dan praktik buerger exercise serta edukasi perawatan kaki dapat dijadikan upaya menurunkan resiko gangguan vaskular dan menguragi resiko komplikasi kaki.
\end{abstract}

Kata Kunci: buerger exercise, perawatan kaki, diabetes, hipertensi

\begin{abstract}
Hypertension and Diabetes Mellitus (DM) are chronic diseases that need continuous treatment to control blood pressure and blood sugar levels. The diseases are susceptible to vascular problems, so that blood circulation is not smooth and made prone to leg disorders that manifest as blockages in blood vessels, ulcers, and even amputations. Covid 19 pandemic requires people with the diseases stay at home if there is no emergency since they are at high risk of being infected. This community service (PKM) aims to provide education and training about Buerger exercises and foot care to reduce the risk of vascular disorders for people with DM and hypertension. The PKM, which took place at the Lembaga Kesejahteraan Sosial Hargo Dedali, Surabaya, with strict health protocols, included 21 participants (around 59 years old); 6 participants have hypertension, 7 participants have DM, and the remaining 8 participants have both diseases. It applied the Community Based Research (CBR) approach. The program's evaluation compared the scores of pre-test and post-test, which assess the participants' knowledge and the examination of foot vascular condition. The results of evaluation are $p=$ $0.000(p<0.05)$ on the knowledge level, $p=0.001(p<0.05)$ on the Vascular Quality of Life, and $A B I$ with $p=0.002(p<0.05)$. The numbers show a significant difference between before and after the program on the level of knowledge and the physical recovery of the vascular. The empowerment of people with DM and hypertension through the education and practice of Buerger exercises and foot care can be used to reduce the risk of vascular disorders and foot complications.
\end{abstract}

Keywords: buerger exercise, foot care, diabetes, hypertension 


\section{Pendahuluan}

Hipertensi dan diabetes melitus (DM) merupakan penyakit kronis yang membutuhkan perawatan berkelanjutan sebagai upaya untuk mengendalikan kadar gula darah dan tekanan darah. Banyak penelitian menemukan hubungan antara peningkatan hipertensi pada pasien dengan penyakit diabetes melitus. Jumlah penderita diabetes di Indonesia setiap tahun meningkat seiring makin bertambahnya penderita hipertensi dan penyakit jantung (Ayuza, 2016). Studi menunjukkan mortalitas kardiovaskuler 2-3 kali lebih tinggi pada penderita diabetes hipertensi dibanding diabetes normotensi (G. P. Sari, Chasani, Pemayun, Hadisaputro, \& Nugroho, 2017).

International Diabetes Federation (IDF) (2014) menyatakan bahwa terdapat 9,1 juta kasus DM dan 4,6 juta kasus DM belum terdiagnosa pada rentang usia 20-79 tahun (International Diabetes Federation, 2017). Prevalensi DM di Indonesia pada tahun 2018 10,9\% (berdasarkan pemeriksaan darah pada penduduk umur $\geq 15$ tahun. Prevalensi penderita DM di Jawa Timur sangat tinggi, berdasarkan laporan Dinas Kesehatan Kota Surabaya sepanjang tahun 2018 dilaporkan sebanyak 114.580 kasus DM (Dinas Kesehatan Kota Surabaya, 2018). Jumlah hipertensi di dunia mencapai 1 miliar dari total penduduk dunia (Mills et al., 2016). Di Indonesia, hasil Riset Kesehatan Dasar (Riskesdas) Balai Penelitian dan Pengembangan Kesehatan (Balitbangkes) Departemen Kesehatan RI tahun 2018 menunjukan prevalensi hipertensi secara nasional mencapai 31,7\% (Riset Kesehatan Dasar (Riskesdas), 2018).

Pasien diabetes yang disertai dengan hipertensi lebih meningkatkan resiko penyakit jantung koroner, stroke, nefropati dan retinopati (Abougalambou \& Abougalambou, 2013). Kondisi DM dan hipertensi memiliki kerentanan mengalami gangguan vaskular yang mengakibatkan aliran sirkulasi darah tidak lancar dan rentan mengalami gangguan terutama pada ekstremitas kaki. Manifestasi yang sering terjadi pada penderita DM akibat gangguan vaskular adalah ulkus diabetikum yang dapat beresiko mengalami amputasi (Al Sayah, Soprovich, Qiu, Edwards, \& Johnson, 2015). Sedangkan pada penderita hipertensi, keluhan yang sering ditemukan ada kaki kesemutan bahkan sumbatan pada pembuluh darah. Hipertensi pada DM tipe 2 juga disebabkan hiperglikemia yang meningkatkan angiostensin II dan menyebabkan terjadinya hipertensi (G. P. Sari et al., 2017). Apabila seseorang terdiagnosa DM dan hipertensi maka sangat diperlukan yaitu pencegahan primer yaitu dengan perawatan kaki sehingga terhindar dari komplikasi gangguan sirkulasi. Ditambah lagi kondisi sekitar wilayah Surabaya yang padat penduduk dan kebersihan yang kurang terjaga menjadikan penderita DM dan hipertensi rentan mengalami permasalahan di kaki yang jika terjadi luka dan tanpa memantau kondisi glukosa darah dan tekanan darah yang baik maka dapat jatuh pada berbagai macam komplikasi pada kaki seperti ulkus.

Berdasarkan pengamatan, pelayanan untuk pasien di pusat layanan kesehatan lebih banyak di fokuskan pada monitoring gula darah, tekanan darah dan pemberian obat untuk pasien DM dan hipertensi. Namun situasi pandemi akibat COVID-19, mengharuskan penderita tetap berada dirumah saja, jika tidak ada situasi darurat. Dampaknya tenaga kesehatan belum dapat melaksanakan penatalaksanaan pasien DM dan hipertensi yang meliputi edukasi, aktivitas 
fisik, terapi nutrisi dan intervensi farmakologis medis. Aktifitas fisik menjadi area yang belum mendapat perhatian dan edukasi yang diberikan hanya dalam bentuk leaflet. Pada hakekatnya ulkus kaki dapat dicegah dengan cara melakukan skrining dini serta edukasi penatalaksanaan kaki diabetes pada individu berisiko tinggi (Alvarsson, Sandgren, Wendel, Alvarsson, \& Brismar, 2012). Berdasarkan informasi yang diperoleh dari beberapa penderita DM yang ditemui di Lembaga Kesejahteraan Sosial Hargo Dedali pada tanggal 27 Agustus 2020 didapatkan bahwa ada yang mengalami kaki kering, muncul kalus pada kaki, sering mengeluh gatal pada kaki atau luka ringan akibat gesekan kulit yang kering. Hal ini beresiko mengakibatkan kondisi gangguan kaki diabetes (ulkus). Perawatan kaki seperti membersihkan kaki, memakai kaus kaki dan tidak berjalan menggunakan alas kaki sehingga terhindar dari komplikasi penyakit diabetes melitus yaitu kaki diabetik (diabetic foot), yang dapat bermanifestasikan sebagai ulkus, infeksi dan gangren dan artropati Charcot (Sharoni, Abdul Rahman, Minhat, Shariff Ghazali, \& Azman Ong, 2017).

Buerger exercise yang dikombinasikan dengan program promosi kesehatan DM dapat memperbaiki gejala neuropati perifer dan sirkulasi perifer pada pasien diabetes tipe 2 (Chang, Chang, Hwang, \& Chen, 2015). Pada buerger exercise, memanfaatkan kekuatan gaya gravitasi yang diaplikasikan oleh otot halus pembuluh darah dan sistem vaskular pada posisi yang berbeda. Gravitasi membantu pengosongan dan pengisian ruang pada pembuluh darah secara bergantian, yang pada akhirnya meningkatkan transportasi darah vaskular. Buerger Exercise terbukti dapat meningkatkan nilai ABI lebih tinggi karena latihan gabungan dari muscle pump (dorsofleksidan plantarfleksi) dan perubahan gravitasi (elevasi kaki $45^{\circ}$, penurunan kaki, tidur terlentang) (A. Sari, Wardy, \& Sofiani, 2019). Buerger exercise didasarkan pada kekuatan gravitasi untuk memperbaiki transportasi darah vaskular, gerakannya sangat sederhana karena terdiri dari tiga gerakan dan tidak memerlukan peralatan khusus sehingga sangat disarankan untuk dapat di praktikkan secara teratur oleh penderita DM dan hipertensi. Kondisi masyarakat ditengah pandemi covid-19 mengharuskan kita berdiam diri dirumah, termasuk penderita DM dan hipertensi sehingga ini dapat menjadi salah satu alternatif latihan yang dapat dilakukan dirumah.

Penelitian sebelumnya diperoleh bahwa buerger exercise yang dikombinasikan dengan program promosi kesehatan tentang salah satunya edukasi perawatan kaki berpengaruh signifikan terhadap perbaikan kondisi sirkulasi kaki berdasarkan pengukuran ankle brachial index (ABI) dan keluhan atas ketidaknyamanan pada kaki (Chang et al., 2015). Berdasarkan pada penjelasan di atas dan sebagai bagian dari tri darma perguruan tinggi, maka melalui kegiatan pengabdian kepada masyarakat berupa "buerger exercise dan edukasi perawatan kaki pada penderita diabetes dan hipertensi dalam upaya menurunkan resiko gangguan vaskular". Kegiatan ini diharapkan mampu meningkatkan pengetahuan terkait materi yang disampaikan dan peningkatan kualitas kondisi vaskular sebagai upaya pencegahan komplikasi pada penderita DM dan hipertensi sehingga tercipta peningkatan derajat kesehatan di masyarakat. 


\section{Metode}

Program pengabdian Kepada Masyarakat ini menggunakan metode pendidikan dan pelatihan tentang kegiatan buerger exercise dan edukasi perawatan kaki pada penderita diabetes dan hipertensi dalam upaya menurunkan resiko gangguan vaskular di Lembaga Kesejahteraan Sosial Hargo Dedali, Surabaya. Materi modul tentang buerger exercise dan edukasi perawatan kaki tersebut telah dimodifikasi untuk orang awam dan disesuaikan dengan kondisi masyarakat di wilayah tersebut. Metode PKM ini melalui pendekatan Community Based Research (CBR) ditandai oleh prinsip-prinsip kolaboratif, berorientasi pada perubahan, dan inklusif yang alur pelaksanaannya dapat dilihat pada gambar 1.

Mitra masyarakat dan pakar akademik bekerja bersama untuk mengembangkan pendidikan dan pelatihan yang responsif terhadap kebutuhan masyarakat, menentukan metode pengumpulan data yang tepat, dan mengembangkan strategi penyebaran pengetahuan yang efektif. Pengembangan metode tersebut dengan penerapan ilmu pengetahuan dan teknologi dengan cara sebagai berikut:

1. Teknologi Informasi Pengetahuan

Kegiatan ini menggunakan ceramah dengan media powerpoint untuk penjelasan dan dilanjutkan dengan diskusi kepada masyarakat (penderita DM dan hipertensi). Kemudian dilakukan pemantapan melalui pre test dan post-test untuk mengukur pemahaman responden terkait materi yang disampaikan dan hasilnya dituliskan melalui pelaporan.

2. Teknologi Pelatihan keterampilan (skills)

Pada kegiatan ini juga dilakukan simulasi/praktik proses penyelesaian masalah latihan Buerger Exercise sehingga dapat dipraktikkan oleh khalayak sasaran dan tercipta kemandirian dan kerjasama dalam pencegahan serta perawatan.

3. Teknologi Pemantapan sikap

Melalui simulasi dan diskusi akan diperoleh pemantapan terkait materi yang diajarkan sehingga muncul interes/penerimaan sikap. Khalayak sasaran dirangsang untuk meningkatkan kepedulian dalam pencegahan dan perawatan.

Materi penyuluhan yang diberikan meliputi: definisi, tujuan, manfaat, indikasi dan kontraindikasi serta langkah-langkah pelaksanaan Buerger Exercise dan Edukasi Perawatan Kaki Sebagai khalayak sasaran adalah penderita DM dan hipertensi sebanyak 21 orang, yang diperoleh dengan cara melakukan koordinasi lanjutan dengan pihak Lembaga Kesejahteraan Sosial Hargo Dedali. Situasi pandemi akibat COVID-19 mengharuskan setiap kegiatan dimasyarakat harus memperhatikan protokol kesehtaan yang ketat. Dalam tahap pelaksanaan ini kegiatan terdiri dari beberapa sesi, pertama yaitu pre test kemudian pemberian materi, praktik buerger exercise dan diskusi kemudian diakhiri dengan post-test.

Kegiatan pre-test dan post-test untuk mengetahui tingkat pemahanan sebelum dan sesudah pelaksanaan kegiatan dan kondisi vaskular peserta melalui Vascular Quality of Life kuesioner dan pegukuran Ankle Brachial Index (ABI). Terdapat 10 pertanyaan pada kuesioner tingkat pengetahuan berupa pertanyaan positif benar salah terkait dengan materi yang akan disampaikan. Vascular Quality of Life kuesioner berisikan 6 pertanyaan dengan skor antara 6- 
24 dimana skor yang lebih tinggi menunjukkan kesehatan yang lebih baik pada kualitas vaskular. Pertanyaan kuesioner meliputi kondisi kaki, jangkauan pergelangan kaki, kemampuan berjalan dan kekhawatiran yang muncul. Kuesioner dapat digunakan untuk mengevaluasi gejala utama dan bagaimana pasien merasakan dampaknya pada kehidupan sehari-hari. Kuesioner ini diketahui memiliki hasil validitas $(r=0.55-0.62)$ yang memili interpretasi baik dan juga nilai reliabilitas (Cronbachs-a 0.82) yang berarti hasilnya juga baik untuk mengevaluasi suatu kondisi (Larsen et al., 2017). Ankle Brachial Index (ABI) adalah test non invasive untuk mengukur rasio tekanan darah sistolik kaki (ankle) dengan tekanan darah sistolik lengan (brachial)). Nilai ABI adalah Hasil pembagian nilai tekanan darah sistolik tertinggi dari kedua ekstremitas pada area ankle dan brachial (Nilai ABI = Tekanan darah sistolik brachialis/ Tekanan darah sistolik ankle). Interpretasi nilai $A B I$ hasil sebagai berikut:

$A B I \geq 0,9-1,3=$ normal

$\mathrm{ABI}<0,9=$ resiko mengalami peripheral arteri desease $(\mathrm{PAD}) /$ penyakit pada pembuluh darah perifer.

Analisa situasi di lokasi mitra PKM meliputi kondisi vaskular kaki

Pendidikan dan pelatihan buerger exercise dan edukasi perawatan kaki dengan menerapkan protokol kesehatan ketat untuk Covid-19

\section{-Hari ke-1:}

-Dilakukan pre-test untuk tingkat pengetahuan terkait materi yang akan disampaikan dan penilaian kondisi vaskular kaki melalui kuesioner vasqular quality of life dan pemeriksaan ABI

-Memberikan materi dan praktik buerger exercise

-Hari ke-2:

-Memberikan materi terkait edukasi perawatan kaki dan meminta mempraktikkan kembali materi hari sebelumnya

-Melaksanakan post-test terkait pengetahuan dan kondisi vaskular

Peningkatan pengetahuan dan derajat kesehatan masyarakat

Gambar 1. Alur Pelaksanaan PKM

Pelaksanaan kegiatan penyuluhan berfokus pada pendidikan dan praktik buerger exercise serta edukasi perawatan kaki, materi disampaikan oleh tim pelaksana kegiatan. Tahap akhir yaitu melakukan evaluasi untuk mengetahui apakah kegiatan pengabdian ini mencapai tujuan 
atau tidak. Evaluasi dilakukan dengan cara membandingkan rata rata nilai tingkat pengetahuan, kuesioner Vascular Quality of Life dan hasil pemeriksaan ABI peserta sebelum dan sesudah dilaksanakan penyuluhan dan praktik. Analisis yang digunakan adalah analisis univariat dan bivariate menggunakan bantuan SPSS. Analisis univariat dimaksudkan untuk untuk mengetahui penyebaran katagori tingkat pengetahuan dan sikap terhadap pencegahan serta perbedaan rata rata nilai sebelum dan sesudah dilaksanakan penyuluhan. Sedangkan analisis bivariat untuk mengetahui peranan karakteristik dalam meningkatkan pengetahuan masyarakat dan gambaran kondisi vaskular kaki. Hasil kegiatan disajikan dalam bentuk distribusi frekuensi.

\section{Hasil dan Pembahasan}

Pelaksanaan kegiatan pengabdian masyarakat dilaksanakan menyasar pada kelompok masyarakat yang resiko gangguan vaskular dan mengalami resiko komplikasi kaki yaitu penderita DM dan hipertensi. Pelaksanaan kegiatan dilaksanakan tanggal 22-23 September 2020 yang dihadiri oleh 21 peserta dengan DM dan hipertensi dengan menerapkan protokol keamanan untuk Covid-19 yang ketat yaitu waktu pelaksanaan kegiatan yang tidak terlalu lama, melakukan physical distancing penaatan kursi untuk peserta, seluruh peserta wajib menggunakan masker dan faceshield, mencuci tangan teratur dengan disediakan handsanitiser oleh penyaji, pengukuran suhu tubuh peserta hadir ruangan dibuka pintu dan jendela untuk memaksimalkan ventilasi. Pertimbangan waktu 2 hari karena menurut John dan Rathiga (2015), Buerger Allen exercise dapat diajarkan pada hari yang sama 2 kali hari dengan interval 6 jam menunjukkan bahwa ada peningkatan yang signifikan pada perfusi ekstremitas bawah (John \& Rathiga, 2015). tersebut karena menurut Kegiatan ini telah mendapatkan ijin dari mitra Lembaga Kesejahteraan Sosial Hargo Dedali dengan No. Surat 723/PW-HD/IX/2020.

Karakteristik dari seluruh peserta PKM adalah wanita berjumlah 21 peserta dengan usia rata-rata peserta adalah 59 tahun dengan tingkat pendidikan mayoritas lulus SMA 33,3\%. Berdasarkan riwayat penyakit yang diderita, terdapat 6 orang $(28,6 \%)$ mengalami hipertensi, 7 orang $(33,3 \%)$ mengalami DM dan 8 orang $(38,1 \%)$ mengalami keduanya. Pelaksaanaan kegiatan ini dengan memperhatikan protokol kesehatan yang ketat dimana di peroleh rerata suhu tubuh peserta sebelum pelatihan (pada hari 1) adalah 36,62 C dan pada hari kedua rerata suhu tubuh peserta yaitu 36,65 C yang mengindikasikan seluruh peserta dalam kondisi suhu tubuh yang normal.

Adapun hasil dari kegiatan pengabdian masyarakat tersaji dalam Tabel 1 berikut ini.

Tabel 1. Hasil tingkat pengetahuan terhadap materi pelatihan

\begin{tabular}{lccc}
\hline & $\begin{array}{c}\text { n (jumlah } \\
\text { peserta) }\end{array}$ & $\begin{array}{c}\text { Mean (minimum- } \\
\text { maksimum) }\end{array}$ & $\mathrm{p}$ \\
\hline Pengetahuan sebelum penyuluhan & 21 & $71,43(50-90)$ & $0,000^{*}$ \\
Pengetahuan sesudah penyuluhan & 21 & $91,43(60-100)$ & \\
\hline
\end{tabular}

*Uji Wilcoxon 


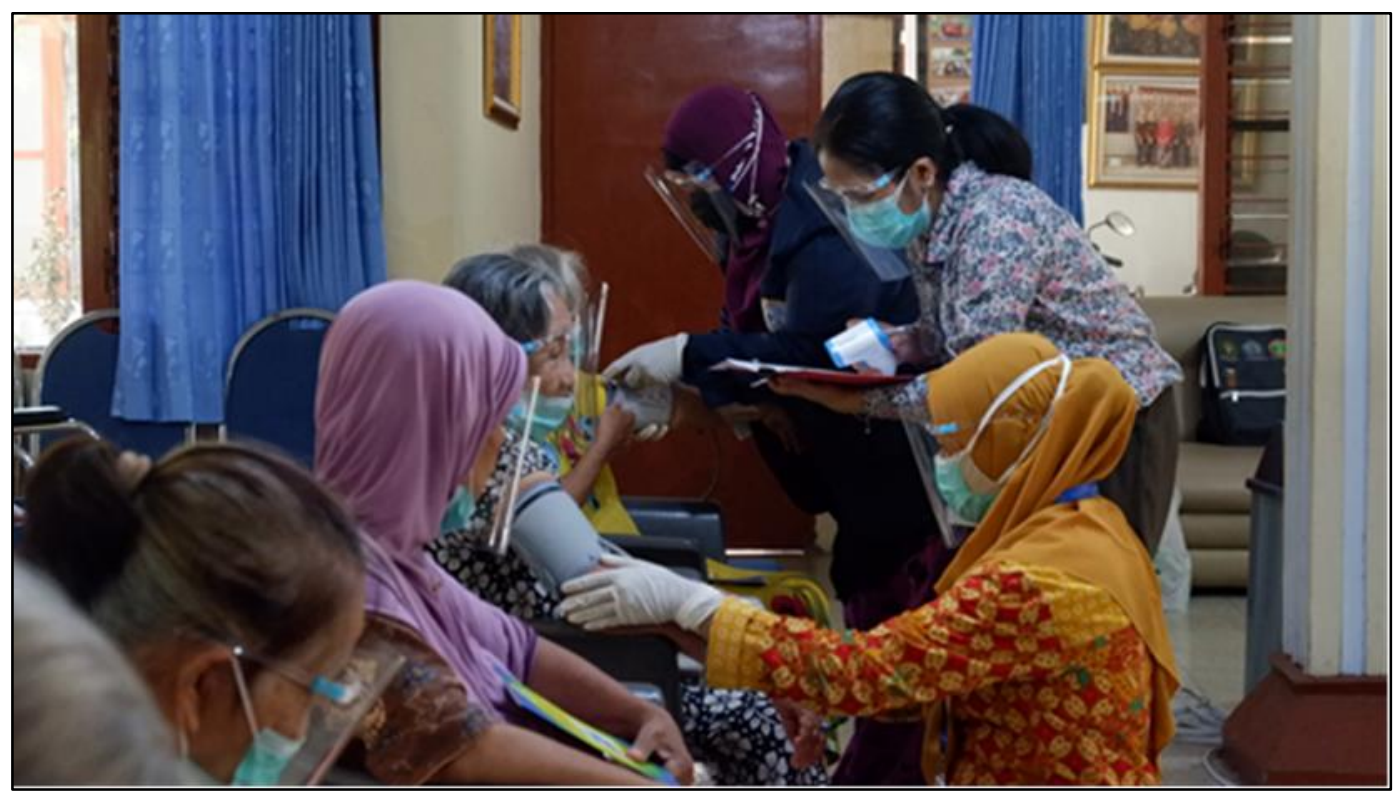

Gambar 2. Pengecekan tekanan darah dan suhu dengan menerapkan protocol yang ketat

Berdasarkan Tabel 1 diatas diperoleh nilai $p=0,000(p<0,05)$ sehingga dapat disimpulkan terdapat perbedaan pengetahuan yang bermakna antara sebelum dan sesudah diberikan pendidikan dan praktik buerger exercise serta edukasi perawatan kaki dengan rincian terdapat 17 orang mempunyai pengetahuan yang lebih baik dari sebelum penyuluhan dan 4 orang dengan nilai sama dengan sebelum penyuluhan.
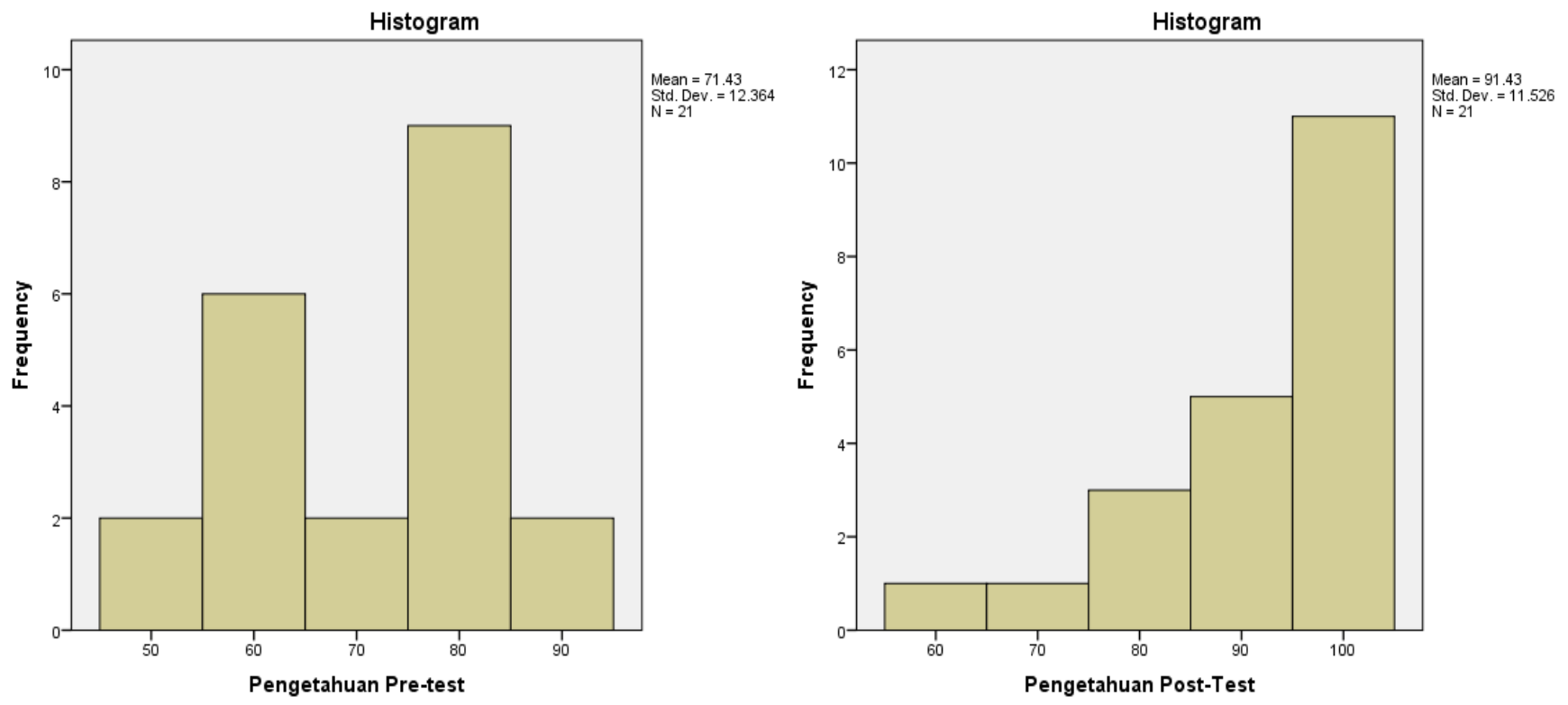

Gambar 3. Diagram frekuensi tingkat pengetahuan peserta penyuluhan

Berdasarkan gambar 3 diatas diperoleh frekuensi tingkat pengetahuan peserta penyuluhan yang menunjukkan sebelum penyuluhan rerata nilai peserta PKM sebesar 71,43 dan setelah penyuluhan didapatkan rerata nilai sebesar 91,43 . Peningkatan rata rata nilai tersebut 
sangat mungkin karena kegiatan penyuluhan yang dilaksanakan sangat disesuaikan dengan kebutuhan peserta penyuluhan. Materi penyuluhan dikemas sehingga menjadi bahan informasi yang sangat mudah untuk dipahami dan menggunakan bahasa yang mudah dipahami oleh orang awam.

Adanya informasi tentang pentingnya pendidikan dan pelatihan buerger exercise dan perawatan kaki bagi kesehatan menjadikan peserta penyuluhan lebih memahami tentang materi yang diberikan. Melakukan perawatan kaki pada pasien sangat penting sekali, guna mencegah terjadinya luka pada kaki (Bharat Kotru, 2015). Komponen perawatan kaki yang dianjurkan untuk pasien DM dan hipertensi meliputi mencuci dan mengeringkan kaki harian, memeriksa kondisi kaki setiap hari, merawat kuku, berhati-hati saat olahraga, serta melindungi kaki dengan sepatu dan kaos kaki (Vatankhah et al., 2009). Tujuan perawatan kaki untuk mengetahui ada kelainan sedini mungkin, menjaga kebersihan kaki dan mencegah perlukaan kaki yang dapat menimbulkan resiko infeksi dan amputasi (van Netten et al., 2016).

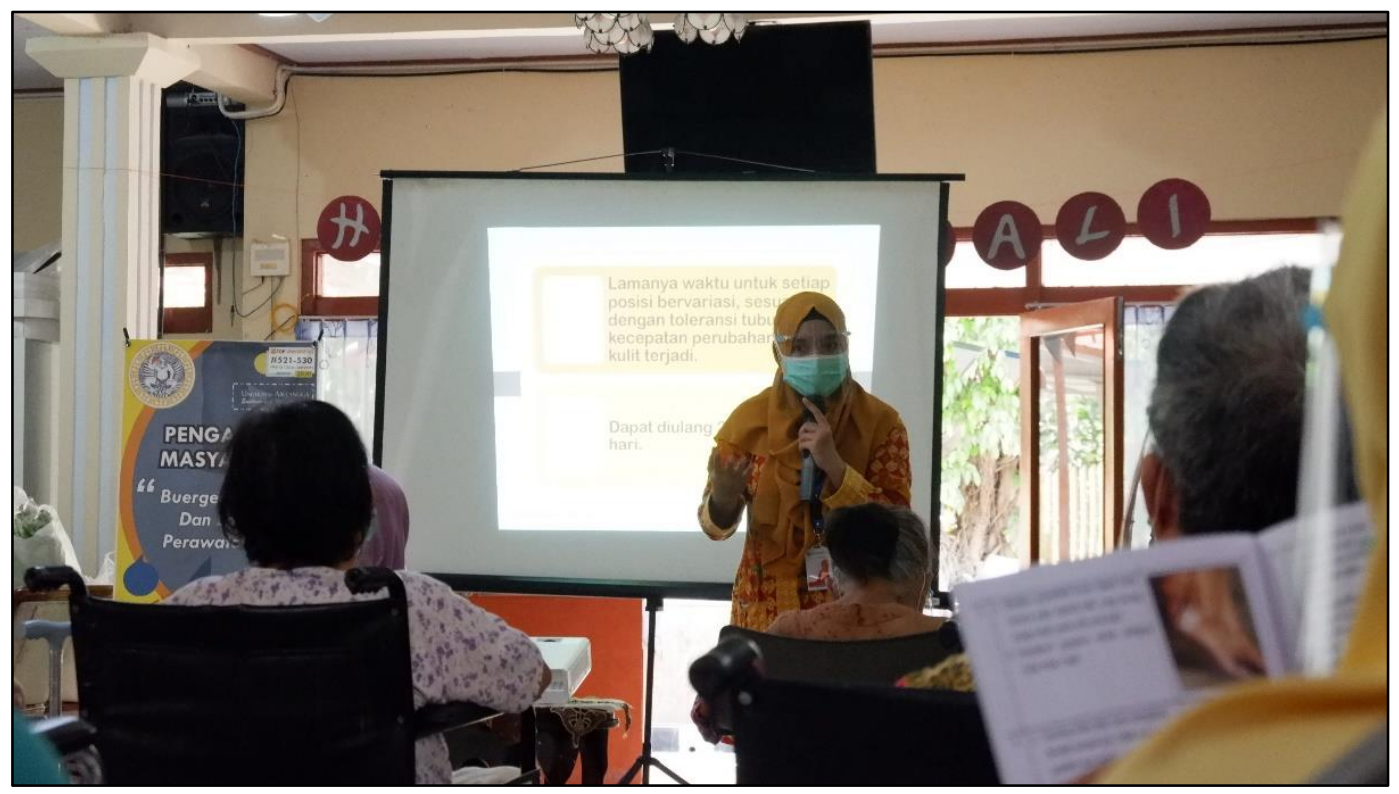

Gambar 4. Kegiatan pemaparan materi

Buerger exercise yang dikombinasikan dengan program promosi kesehatan DM dapat memperbaiki gejala neuropati perifer dan sirkulasi perifer pada pasien diabetes tipe 2 (Chang et al., 2015). Pada buerger exercise, memanfaatkan kekuatan gaya gravitasi yang diaplikasikan oleh otot halus pembuluh darah dan sistem vaskular pada posisi yang berbeda. Gravitasi membantu pengosongan dan pengisian ruang pada pembuluh darah secara bergantian, yang pada akhirnya meningkatkan transportasi darah vaskular. Buerger Exercise terbukti dapat meningkatkan nilai ABI lebih tinggi karena latihan gabungan dari muscle pump (dorsofleksidan plantarfleksi) dan perubahan gravitasi (elevasi kaki $45^{\circ}$, penurunan kaki, tidur terlentang) (A. Sari et al., 2019). 
Tabel 2. Hasil Kuesioner Vascular Quality of Life

\begin{tabular}{lccc}
\hline & $\mathrm{n}$ (jumlah peserta) & Mean (minimum-maksimum) & $\mathrm{p}$ \\
\hline $\begin{array}{l}\text { Kuesioner Vascular Quality of } \\
\text { Life sebelum penyuluhan }\end{array}$ & 21 & $10,24(7-17)$ & $0,001^{*}$ \\
$\begin{array}{l}\text { Kuesioner Vascular Quality of } \\
\text { Life penyuluhan }\end{array}$ & 21 & $13,48(8-17)$ & \\
\hline
\end{tabular}

*Uji Wilcoxon

Berdasarkan tabel 2 diatas diperoleh nilai $p=0,001(p<0,05)$ sehingga dapat disimpulkan terdapat perbedaan Vascular Quality of Life yang bermakna antara sebelum dan sesudah diberikan pendidikan dan praktik buerger exercise serta edukasi perawatan kaki dengan rincian terdapat 16 orang mempunyai Vascular Quality of Life yang lebih baik dari sebelum penyuluhan, 4 orang mempunyai Vascular Quality of Life yang lebih rendah dari sebelum penyuluhan dan 1 orang dengan nilai 16 orang mempunyai Vascular Quality of Life yang lebih baik dari sebelum penyuluhan sama dengan sebelum penyuluhan.

Tabel 3. Hasil ABI sebelum dan sesudah pelatihan

\begin{tabular}{lccccc}
\hline & $\begin{array}{c}\mathrm{n} \text { (jumlah } \\
\text { peserta) }\end{array}$ & Mean \pm SD & $\begin{array}{c}\text { Perbedaan } \\
\text { rerata } \pm \text { SD }\end{array}$ & IK95\% & $\mathrm{p}$ \\
\hline ABI sebelum penyuluhan & 21 & $0,88 \pm 0,16$ & $0,20 \pm 0,26$ & $0.08-0.32$ & $0,002 * *$ \\
ABI sesudah penyuluhan & 21 & $1,08 \pm 0,19$ & & & \\
\hline
\end{tabular}

**uji t berpasangan

Berdasarkan tabel 3 diatas diperoleh nilai $p=0,002(p<0,05)$ sehingga dapat disimpulkan terdapat perbedaan $\mathrm{ABI}$ yang bermakna antara sebelum dan sesudah diberikan pendidikan dan praktik buerger exercise serta edukasi perawatan kaki dengan selisih ABI sebelum dan ssesudah penyuluhan antara 0,08-0,32.

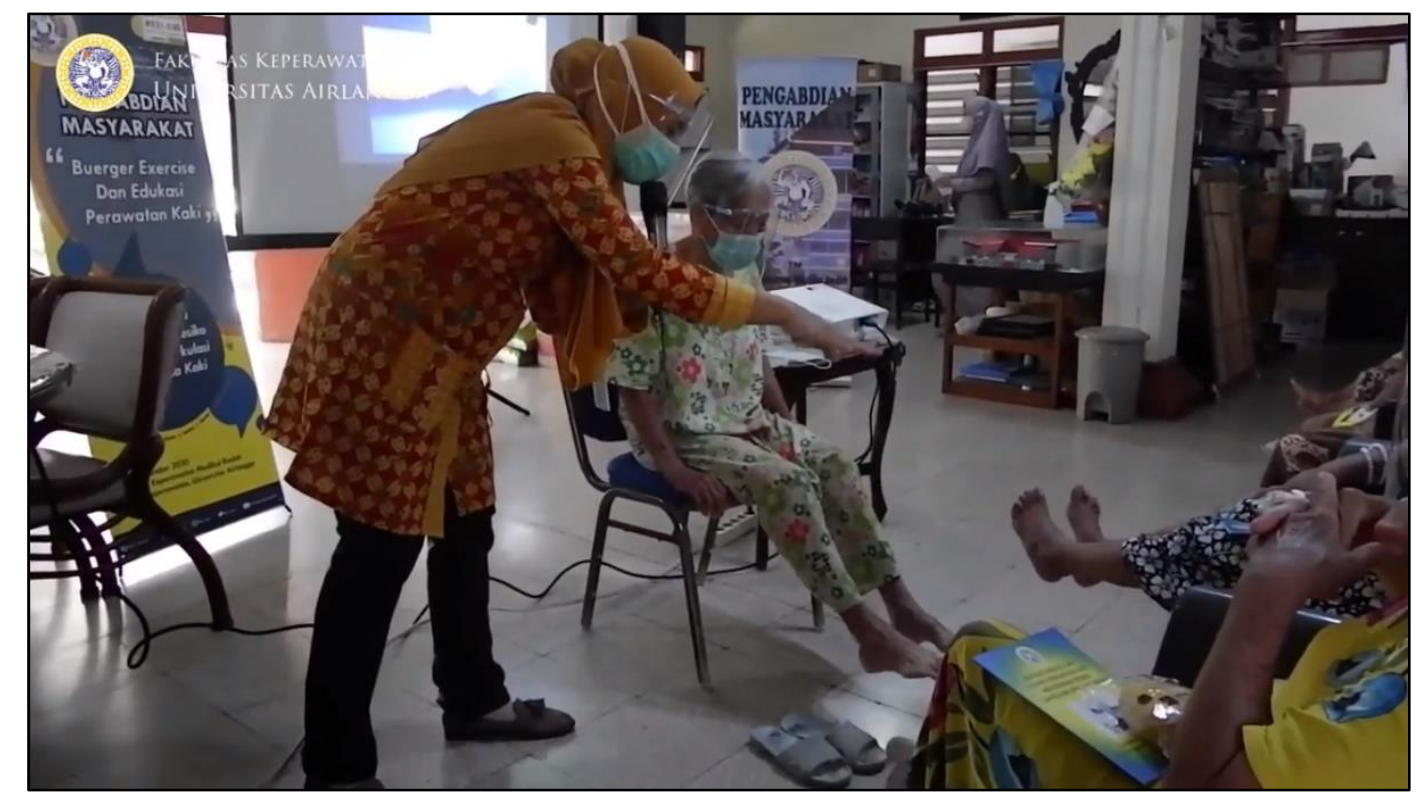

Gambar 5. Kegiatan praktik Buerger exercise bagi peserta 
Gejala primer PAD pada batasan perfusi berupa nyeri pada pantat/betis ketika berjalan (klaudikasio intermiten) mulai terasa. Proses penuaan yang mengakibatkan perubahan dinding pembuluh darah sehingga mempengaruhi transportasi oksigen dannutrisi ke jaringan. Lapisan intima menebal sebagai akibat proliferasi seluler dan fibrosis. Serabut di lapisan media mengalami kalsifikasi,tipis dan terpotong, serta kolagen yang menumpuk di lapisan intimadan media. Perubahan tersebut menyebabkan kekakuan pembuluhdarah, yang mengakibatkan peningkatan tekanan pembuluh perifer,ganguan aliran darah, dan peningkatan kerja ventrikel kiri (Brunner, Suddarth, \& Smeltzer, 2008). Latihan fisik yang teratur dan terkontrol dapat memperlancar sirkulasi darah sehingga mengurangi terjadinya obstruksi terutama pada pembuluh perifer (Matos, Mendes, Silva, \& Sousa, 2018).

Berdasarkan hasil penelitian yang pernah dilakukan didapatkan bahwa buerger exercise yang dilakukan sebanyak 2 kali sehari dengan waktu latihan 17 sampai 20 menit, selama 3 minggu efektif untuk meningkatkan sirkulasi luka kaki karena perubahan posisi dan gaya gravitasi membantu mengosongkan dan mengisi kolom darah, sedangkan kontraksi muskulus gastrocnemius sebagai muscle pump mengaktivasi pembuluh darah vena dan arteri untuk membuka jalur sirkulasi collateral lokal (Jannaim, Dharmajaya, \& Asrizal, 2018). Penelitian lainnya menyatakan bahwa Buerger allen exercise dilakukan 2 kali sehari selama 5 hari dengan durasi 15 menit dapat meningkatkan skor ABI yang menandakan perbaikan sirkulasi eprifer pada pasien ulkus kaki diabetik (A. Sari et al., 2019). Sedangkan menurut John dan Rathiga (2015), Buerger Allen exercise dapat diajarkan pada hari yang sama 2 kali hari dengan interval 6 jam menunjukkan bahwa ada peningkatan yang signifikan pada perfusi ekstremitas bawah. Melakukan elevasi kaki selama 5 menit setiap 2 jam secara berulang dapat meningkatkan sirkulasi dan bermanfaat besar pada insufisiensi vena ektremitas bawah pasien dengan luka kaki diabetes (John \& Rathiga, 2015).

Tim pelaksana melakukan koordinasi dengan pihak Lembaga Kesejahteraan Sosial Hargo Dedali untuk monitoring dan evaluasi untuk keberlanjutan program ini dengan harapan program pendidikan dan pelatihan tentang kegiatan Buerger Exercise Dan Edukasi Perawatan Kaki Dalam Upaya Menurunkan Resiko Gangguan Sirkulasi Darah Pada Kaki Penderita Diabetes dan Hipertensi dapat diinformasikan kepada masyarakat luas baik oleh keluarga, petugas yayasan maupun penderita itu sendiri.

\section{Kesimpulan}

Pemberdayaan penderita DM dan hipertensi melalui pendidikan dan praktik buerger exercise serta edukasi perawatan kaki dapat dijadikan upaya menurunkan resiko gangguan vaskular dan menguragi resiko komplikasi kaki. Buerger exercise terdiri dari tiga gerakan yang relative mudah di lakukan dan tidak memerlukan peralatan khusus sehingga serta memiliki manfaat yang besar sehingga diharapkan dapat diimplementasikan secara rutin oleh peserta PKM. Kegiatan pengabdian masyarakat yang dilakukan dapat membentuk mengembangkan sekelompok masyarakat yang membantu menciptakan ketentraman, kenyamanan dalam kehidupan bermasyarakat yang sehat di wilayah Surabaya yang dalam hal ini bekerjasama 
dengan mitra Lembaga Kesejahteraan Sosial Hargo Dedali, Surabaya yang memfasilitasi terlaksananya kegiatan penyuluhan ditengah situasi pandemi akibat COVID-19 dengan menerapkan protokol kesehatan yang ketat.

\section{Ucapan Terima Kasih}

Penulis menyampaikan terimakasih kepada semua pihak yang telah membantu dalam pelaksanaan kegiatan Program Pengabdian Masyarakat ini. Secara khusus penulis ingin mengucapkan terimakasih dan penghargaan yang setinggi-tingginya kepada Rektor Universitas Airlangga dan Dekan fakultas Keperawatan Universitas Airlangga atas kesempatan dan dukungan yang telah diberikan kepada penulis untuk dapat melaksanakan kegiatan Program Pengabdian Masyarakat ini. Penulis juga menyampaikan terimakasih kepada Kepala Lembaga Kesejahteraan Sosial Hargo Dedali, serta para peserta PKM atas kesempatan dan partisipasinya dalam pelaksanaan kegiatan Program Pengabdian Masyarakat ini.

\section{Referensi}

Abougalambou, S. S. I., \& Abougalambou, A. S. (2013). A study evaluating prevalence of hypertension and risk factors affecting on blood pressure control among type 2 diabetes patients attending teaching hospital in Malaysia. Diabetes and Metabolic Syndrome: Clinical Research and Reviews, 72), 83-86. https://doi.org/10.1016/j.dsx.2013.02.019

Al Sayah, F., Soprovich, A., Qiu, W., Edwards, A. L., \& Johnson, J. A. (2015). Diabetic Foot Disease, Self-Care and Clinical Monitoring in Adults with Type 2 Diabetes: The Alberta's Caring for Diabetes (ABCD) Cohort Study. Canadian Journal of Diabetes, 39(3), S120-S126. https://doi.org/10.1016/j.jcjd.2015.05.006

Alvarsson, A., Sandgren, B., Wendel, C., Alvarsson, M., \& Brismar, K. (2012). A retrospective analysis of amputation rates in diabetic patients: can lower extremity amputations be further prevented? Cardiovasc Diabetol, 11, 18. https://doi.org/10.1186/1475-2840-11-18

Ayuza, D. (2016). Diabetes Mellitus Tipe 2 dan Hipertensi Tahap 2 pada Pria Lansia dengan Pola Makan yang Tidak Sehat. J Medula Unila, 4(3), 22-29. Retrieved from https://www.google.com/url?sa $=$ t\&rct $=j \& q=\& e s r c=s \&$ source $=$ web\&cd $=1 \& \mathrm{cad}=$ rja\&uact $=8 \& \mathrm{v}$ ed=2ahUKEwi4pbz4wofmAhXv63MBHYyABkwQFjAAegQIAxAC\&url=http\%3A\%2F\%2Fjuke.ked okteran.unila.ac.id\%2Findex.php\%2Fmedula\%2Farticle\%2FviewFile\%2F1581\%2Fpdf\&usg=A OvVaw3oJ43jLBpCDkc-30

Bharat Kotru, S. K. (2015). Intervention of Diabetes Foot Care Practices on the Prevention of New Diabetic Foot Ulcers in Patients with Type 2 Diabetes Mellitus. Journal of Diabetes \& Metabolism, 06(02). https://doi.org/10.4172/2155-6156.1000494

Brunner, L. S., Suddarth, D. S., \& Smeltzer, S. C. O. (2008). Brunner \& Suddarth's textbook of medical-surgical nursing (11th ed.). Philadelphia: Lippincott Williams \& Wilkins.

Chang, C.-F., Chang, C.-C., Hwang, S.-L., \& Chen, M.-Y. (2015). Effects of Buerger Exercise Combined Health-Promoting Program on Peripheral Neurovasculopathy Among Community Residents at High Risk for Diabetic Foot Ulceration. Worldviews on Evidence-Based Nursing, 12(3), 145-153. https://doi.org/10.1111/wvn.12091

Dinas Kesehatan Kota Surabaya. (2018). Profil Kesehatan Tahun 2018. Surabaya: Dinas Kesehatan Pemerintah Kota Surabaya, http://dinkes.surabaya.go.id/portalv2/publikasi-da. Retrieved from http://dinkes.surabaya.go.id/portalv2/publikasi-data-dan-informasi/

International Diabetes Federation. (2017). IDF Diabetes Atlas Eighth Edition 2017. In International Diabetes Federation, ISBN: 978-2-930229-87-4, www.diabetesatlas.org.

Jannaim, J., Dharmajaya, R., \& Asrizal, A. (2018). Pengaruh Buerger Allen Exercise Terhadap Sirkulasi Ektremitas Bawah Pada Pasien Luka Kaki Diabetik. Jurnal Keperawatan Indonesia, 21(2), 101-108. https://doi.org/10.7454/jki.v21i2.652 
John, J., \& Rathiga, A. (2015). Effectiveness of Buerger Allen Exercise to Improve the Lower Extremity Perfusion among Patients with Type 2 Diabetes Mellitus. International Journal of Current Research and Academic Review, 3(4), 358-366. Retrieved from http://www.ijcrar.com/vol-3-4/Jemcy John and A.Rathiga.pdf

Larsen, A. S. F., Reiersen, A. T., Jacobsen, M. B., Kløw, N. E., Nordanstig, J., Morgan, M., \& Wesche, J. (2017). Validation of the Vascular quality of life questionnaire -6 for clinical use in patients with lower limb peripheral arterial disease. Health and Quality of Life Outcomes, 15(1). https://doi.org/10.1186/s12955-017-0760-3

Matos, M., Mendes, R., Silva, A. B., \& Sousa, N. (2018). Physical activity and exercise on diabetic foot related outcomes: A systematic review. Diabetes Res Clin Pract, 139, 81-90. https://doi.org/10.1016/j.diabres.2018.02.020

Mills, K. T., Bundy, J. D., Kelly, T. N., Reed, J. E., Kearney, P. M., Reynolds, K., ... He, J. (2016). Global Disparities of Hypertension Prevalence and Control: A Systematic Analysis of Populationbased Studies from 90 Countries. Physiology \& Behavior, 134(6), 441-450. https://doi.org/10.1161/CIRCULATIONAHA.115.018912.Global

Riset Kesehatan Dasar (Riskesdas). (2018). Badan Penelitian dan Pengembangan Kesehatan Kementerian RI tahun 2018. Http://Www.Depkes.Go.Id/Resources/Download/Infoterkini/Materi_rakorpop_20 18/Hasil\%20Riskesdas\%202018.Pdf-.

Sari, A., Wardy, A., \& Sofiani, Y. (2019). Efektifitas Perbandingan Buerger Allen Exercise dan Senam Kaki Terhadap Nilai ABI Pada Penderita DM Tipe II. Journal of Telenursing(JOTING), 1(1), 1 16. https://doi.org/https://doi.org/10.31539/joting.v1i1.492

Sari, G. P., Chasani, S., Pemayun, T. G. D., Hadisaputro, S., \& Nugroho, H. (2017). Faktor Risiko yang Berpengaruh terhadap Terjadinya Hipertensi pada Penderita Diabetes Melitus Tipe II di Wilayah Puskesmas Kabupaten Pati. Jurnal Epidemiologi Kesehatan Komunitas, 2(2), 54-61. https://doi.org/10.33658/jl.v13i1.92

Sharoni, S. K. A., Abdul Rahman, H., Minhat, H. S., Shariff Ghazali, S., \& Azman Ong, M. H. (2017). A self-efficacy education programme on foot self-care behaviour among older patients with diabetes in a public long-term care institution, Malaysia: A Quasi-experimental Pilot Study. BMJ Open, 76), 1-11. https://doi.org/10.1136/bmjopen-2016-014393

van Netten, J. J., Price, P. E., Lavery, L. A., Monteiro-Soares, M., Rasmussen, A., Jubiz, Y. International Working Group on the Diabetic, F. (2016). Prevention of foot ulcers in the at-risk patient with diabetes: a systematic review. Diabetes Metab Res Rev, 32 Suppl 1, 84-98. https://doi.org/10.1002/dmrr.2701

Vatankhah, N., Khamseh, M. E., Jahangiri Noudeh, Y., Aghili, R., Baradaran, H. R., \& Safai Haeri, N. (2009). The effectiveness of foot care education on people with type 2 diabetes in Tehran, Iran. Primary Care Diabetes, 3(2), 73-77. https://doi.org/10.1016/j.pcd.2009.05.003 